\title{
Panta rhei
}

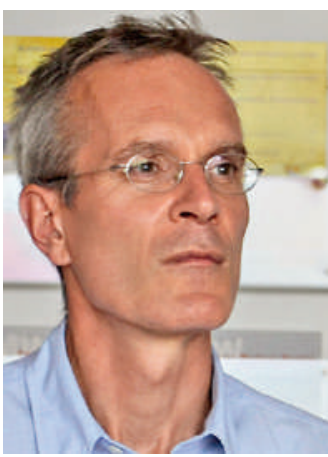

Bruno Kesseli
Schon die alten Griechen wussten: Leben bedeutet Bewegung, bedeutet ständige Veränderung. «Panta rhei» (alles fliesst), soll der Philosoph Heraklit vor rund zweieinhalbtausend Jahren sinngemäss formuliert haben. Ein Gesetz, das auch für die Schweizerische Ärztezeitung Gültigkeit hat.

Die augenfälligste Veränderung bei der SÄZ im zu Ende gehenden Jahr hängt direkt mit dem Wechsel an der Spitze der FMH zusammen. Mit der vor knapp zwei Wochen erfolgten Übernahme der Amtsgeschäfte von Jacques de Haller hat der neue Präsident Jürg Schlup seinen Vorgänger auch als einen von zwei «offiziellen» Vertretern der FMH in der SÄZRedaktion abgelöst. Dieser Wechsel ist insofern weit mehr als eine Fussnote, als Jacques de Haller während seiner achteinhalbjährigen Amtszeit mit der SÄZ eng verbunden war: Als Redaktionsmitglied, das zu jeder Tages- und Nachtzeit für Anfragen und Diskussionen zur Verfügung stand, als FMH-Präsident, der die redaktionelle Unabhängigkeit hochhielt und wenn nötig verteidigte, und natürlich als Autor, der die Standpunkte der FMH in prägnanter und unverwechselbarer Weise zu vermitteln wusste. Wenn sich die SÄZ in den letzten acht Jahren publizistisch zum Positiven weiterentwickelt hat - und ich bin der Meinung, dass dies der Fall war - so hat Jacques de Haller zweifellos wesentlichen Anteil daran. Es ist mir ein Bedürfnis, ihm an dieser Stelle für sein umfassendes Engagement herzlich zu danken, und ich bin mir sicher, dass unsere Leserinnen und Leser Jacques de Haller auch in der Ärztezeitung wieder begegnen werden.

Wie geht es nun weiter? Erfreulicherweise lässt der neue FMH-Präsident Jürg Schlup keine Zweifel daran aufkommen, dass ihm die publizistischen Pfeiler, die das SÄZ-Konzept tragen, ebenfalls sehr am Herzen liegen. Sowohl die redaktionelle Unabhängigkeit als auch die Funktion der SÄZ als offene Plattform, die der freien Meinungsäusserung der Ärzteschaft und aller übrigen am Gesundheitswesen beteiligten Kreise dient, werden im offiziellen Organ der FMH weiterhin von zentraler Bedeutung sein. «Als Präsident der FMH werde ich grosses Gewicht legen auf diese offene Diskussionskultur. Ich kann mir vorstellen, dass wir zu diesem Zweck auch die SÄZ vermehrt als Forum für den Austausch kontroverser Meinungen nutzen», hält Jürg Schlup in seinem Editorial in der letzten Ausgabe fest [1].

Mit seinem Eintritt in die Redaktion der SÄZ signalisiert Jürg Schlup unmissverständlich, dass er der Kommunikation einen hohen Stellenwert beimisst, sei es innerhalb der Ärzteschaft, sei es mit den Partnern im Gesundheitswesen und der breiteren Öffentlich- keit. In mehreren persönlichen Begegnungen durfte ich ihn bereits als interessierten und differenzierten Gesprächspartner erleben, der auch sehr gut zuhören kann und sich in der Tat an einem von ihm gern zitierten Leitsatz des Philosophen Hans-Georg Gadamer orientiert: «Ein Gespräch setzt voraus, dass der andere recht haben könnte.» Ich freue mich auf die $\mathrm{Zu}$ sammenarbeit mit Jürg Schlup und heisse ihn in der Redaktion herzlich willkommen.

Was «fliesst» sonst noch bei der SÄZ? Was die Printausgabe betrifft, werden wir uns im neuen Jahr im Dialog mit dem Präsidenten und den Führungsgremien der FMH sicher darüber Gedanken machen, ob im redaktionellen Bereich unter Berücksichtigung der vorhandenen Ressourcen noch Verbesserungspotential besteht. Ziel wird es bleiben, das duale Konzept mit dem «Spagat» zwischen offiziellem Verbandsorgan und freier Informations- und Meinungsplattform optimal zu gewährleisten. Auch über eine Auffrischung des Layouts darf sechs Jahre nach der letzten Anpassung wieder einmal ernsthaft nachgedacht werden. Substantielle Veränderungen stehen im Online-Bereich an: Hier möchten wir die Möglichkeiten des Mediums Internet besser nutzen und aktueller, interaktiver und benutzerfreundlicher werden. Einerseits ist dies schlicht ein Erfordernis der Zeit, andererseits werden insbesondere seitens jüngerer Kolleginnen und Kollegen auch immer wieder konkrete Wünsche in Bezug auf die elektronischen Angebote an uns herangetragen, denen wir so weit wie möglich zu entsprechen versuchen.

Auch wenn bei der SÄZ vieles im Fluss ist: Einiges wird auch im neuen Jahr gleich bleiben. Eine wichtige Konstante ist die personelle Zusammensetzung der Redaktion. Abgesehen vom erwähnten Wechsel, der durch die Veränderungen an der FMH-Spitze bedingt ist, wird das bisherige Redaktionsteam auch im nächsten Jahr zusammenarbeiten. Für mich eine sehr positive Perspektive, macht doch die Arbeit in diesem gut eingespielten und kompetenten Gremium grosse Freude. Auch meinen Redaktionskolleginnen und -kollegen sei an dieser Stelle für ihren unermüdlichen Einsatz herzlich gedankt.

Und Ihnen, liebe Leserinnen und Leser, danke ich für die Treue, die Sie der SÄZ halten, auch wenn wir gelegentlich Ihre Toleranzschwelle strapazieren. Ich wünsche Ihnen frohe Festtage und einen guten Start ins neue Jahr.

Bruno Kesseli, Chefredaktor

1 Schlup J. Was uns verbindet, ist unser Beruf als Arzt, was uns unterscheidet, ist unsere fachliche Ausrichtung. Schweiz Ärztezeitung. 2012;93(50):1843. 